\title{
Options for National Parks and Reserves for Adapting to Climate Change
}

\author{
Jill S. Baron · Lance Gunderson · Craig D. Allen • \\ Erica Fleishman · Donald McKenzie - Laura A. Meyerson • \\ Jill Oropeza $\cdot$ Nate Stephenson
}

Received: 21 August 2008/Accepted: 12 March 2009/Published online: 16 May 2009

(C) The Author(s) 2009. This article is published with open access at Springerlink.com

\begin{abstract}
Past and present climate has shaped the valued ecosystems currently protected in parks and reserves, but future climate change will redefine these conditions. Continued conservation as climate changes will require thinking differently about resource management than we have in the past; we present some logical steps and tools for doing so. Three critical tenets underpin future management plans and activities: (1) climate patterns of the past will not be the climate patterns of the future; (2) climate defines the environment and influences future trajectories of the distributions of species and their habitats; (3) specific management actions may help increase the resilience of some natural resources, but fundamental changes in species and their environment may be inevitable. Science-based management will be necessary because past experience may not serve as a guide for novel future conditions. Identifying resources and processes at risk, defining thresholds and reference conditions, and establishing
\end{abstract}

J. S. Baron $(\bowtie)$

U.S. Geological Survey, Fort Collins, CO, USA

e-mail: jill@nrel.colostate.edu

\section{J. S. Baron · J. Oropeza}

Natural Resource Ecology Laboratory, Colorado State

University, Fort Collins, CO 80523-1499, USA

\section{Gunderson}

Department of Environmental Studies, Emory University,

Atlanta, GA 30322, USA

C. D. Allen

U.S. Geological Survey, Jemez Mountain Field Station, Los

Alamos, NM 87544, USA

E. Fleishman

National Center for Ecological Analysis and Synthesis,

University of California, Santa Barbara, CA 93101, USA monitoring and assessment programs are among the types of scientific practices needed to support a broadened portfolio of management activities. In addition to the control and hedging management strategies commonly in use today, we recommend adaptive management wherever possible. Adaptive management increases our ability to address the multiple scales at which species and processes function, and increases the speed of knowledge transfer among scientists and managers. Scenario planning provides a broad forward-thinking framework from which the most appropriate management tools can be chosen. The scope of climate change effects will require a shared vision among regional partners. Preparing for and adapting to climate change is as much a cultural and intellectual challenge as an ecological challenge.

Keywords Adaptation - Climate change .

National parks · Reserves - Uncertainty ·

Scenario planning $\cdot$ Adaptive management

D. McKenzie

U.S.D.A. Forest Service, Pacific Northwest Research Station, Seattle, WA 98103, USA

L. A. Meyerson

College of Environment and Life Sciences, University of Rhode Island, Kingston, RI 02881-2020, USA

Present Address:

J. Oropeza

Water Department, City of Fort Collins, Fort Collins, CO 80521, USA

N. Stephenson

U.S. Geological Survey, Sequoia and Kings Canyon Field

Station, Three Rivers, CA 93271-9651, USA 


\section{Introduction}

Climate change imposes fundamentally new and different management problems for park and reserve managers. Many resource agencies build management plans around the concepts of dynamic equilibrium and stationarity, where past conditions and processes provide the context and guidance for contemporary management (Landres and others 1999; Milly and others 2008), but the most basic condition for equilibrium, that of a stable climate, is no longer met (IPCC 2007). With uncertain future climates, managing processes or species to fluctuate within a historic range of variability can no longer be the only appropriate goal. Instead, the research and management communities will need to adjust internal and external expectations and facilitate adjustments of ecosystems to new conditions. Adaptation to climate change, rather than resistance to it, is the best option for protecting valued resources (Millar and others 2007; Baron and others 2008).

Successful adaptation to climate change rests on three critical tenets:

1. Climate patterns of the past will not be the climate patterns of the future. Future climates in parks and reserves may not even settle into new and unfamiliar patterns, but instead continue fluctuating for the foreseeable future.

2. Interactions between temperature and precipitation define the environment of parks and reserves and the interactions between physical and biological processes. Accordingly, climate change cannot be considered merely as one more management issue added to an already long list. Changing climate will, in most cases, amplify the effects from other human-caused disturbances such as fragmentation of land cover or contaminants. Climate change will influence the future trajectories of species and distribution of their habitats, and some proportion of species currently residing within a reserve may migrate outside park or reserve boundaries (Araújo and others 2004). With biotic and abiotic changes in parks and reserves, new ecosystems will appear and existing ones will disappear (Williams and others 2007; Hobbs and others 2006).

3. Specific resource management actions may help increase resilience, defined as the amount of change or disturbance a system can absorb before it undergoes a fundamental shift to a different state (Gunderson 2000; Holling 1973). Fundamental shifts may be inevitable, however, because the climate is changing. Questions of reversibility and irreversibility of ecological states must become part of evaluating and reevaluating the effectiveness of any management actions.
Table 1 Potential steps to implementing adaptations to climate change for parks and reserves

1. Reduce other human-caused stresses to park and reserve ecosystems

2. Identify resources and processes at risk from climate change

Explicitly consider thresholds and consequences of exceeding thresholds

3. Define reference conditions

4. Develop monitoring and assessment programs for resources and processes at risk from climate change

5. Review the language and interpretations of laws, policies, and management guidelines for their continued applicability to management under climate change

6. Diversify the portfolio of management approaches to include adaptive management and scenario planning

7. Foster a culture of trust that promotes and rewards a transparent intellectual process for decision-making at all levels

8. Assess, plan, and manage at multiple scales, letting the issues define the appropriate scales of time and space

9. Form partnerships with other resource management entities

In this article we present guidelines for the management of natural resources within protected national parks and similarly managed reserves under continuing climate change (Table 1). Our examples are drawn from the 270 U.S. National Park areas with natural resource responsibilities, but the adaptation approaches are applicable to diverse resources and sites, including cultural and historical parks and reserves and protected lands both inside and outside the United States. Our discussion is purposefully general, with the intent of stimulating proactive modes of thinking and acting in the face of climate change and other environmental changes. Not only would it be presumptuous to tender specific management recommendations for the large diversity of protected areas worldwide, it would also be wrong. The rate and magnitude of change in any given protected area is not known with certainty and the environmental responses to climate change may be complex and surprising. Thinking about and managing natural resources when the past is no longer an appropriate guide poses intellectual and cultural challenges for researchers and for managers of protected areas. The guidelines we present rest on two considerations: there must be a systematic scientific approach toward understanding natural resources; and natural-resource professionals should embrace new ways of thinking about and managing for natural resource protection when the future is uncertain.

\section{A Systematic, Scientific Approach for Understanding Natural Resources}

Specific activities described below form a foundation for initiating and maintaining climate change-related 
management. These include prioritizing the resources and processes at risk from climate change, identifying climate change-related thresholds between desirable and undesirable conditions, establishing reference conditions for protection or restoration, developing monitoring and assessment programs, and developing models of how systems could change. Together, these are the fundamentals of applying the scientific method to natural resource management (Parsons 2004).

\section{Prioritizing Resources and Processes at Risk}

Systematic and repeated characterization of potential climate change effects on resources is important for prioritizing where to focus scarce time, money, and effort. Characterization begins with a broad understanding of natural resources and their drivers, and can be accomplished through summaries of the literature, guided research, gatherings of experts, and workshops where scientists, managers, and the public discuss risks to resources. We caution against the tendency to insist on high-precision climate forecasts before undertaking this exercise. Detailed and site-specific climate forecasts may be helpful for specific applications, but general projections (e.g., warmer, greater variability in precipitation and temperature) may be sufficient for the initial stages of risk assessment. Subsequent iterations of the exercise can quantify resource risk in more detail according to the urgency and capacity of available resources to achieve desired management goals (Millar and others 2007). Not all resources will respond negatively or rapidly.

\section{Climate-Related Thresholds}

Assessment of risk requires explicit consideration of where thresholds lie and how crossing thresholds will affect valued species, communities, ecosystem processes, and their interactions. An ecological threshold has been defined as an abrupt or relatively rapid change in an ecosystem quality, property, or phenomenon (Groffman and others 2006). Climate change provides the impetus to identify not only societally acceptable versus unacceptable change, but controllable versus uncontrollable change. Some threshold concepts, including critical loads, are already used by national parks in the United States and Europe. A critical load is the value of atmospheric pollution deposition below which there is no discernable ecological effect (Porter and Johnson 2007). Effects of crossing climate change-related thresholds might include extirpation or extinction of species due to loss of climate envelopes, changes in fire regimes, or expansion of nonnative invasive species (McKenzie and others 2004; Williams and others 2007).
Establishing Reference Conditions for Protection or Restoration

Reference conditions describe the standard or benchmark against which current or future conditions can be compared (Stoddard and others 2006). Reference conditions can define an environmental condition in the absence of human disturbance, as suggested by Stoddard and others (2006). Reference conditions can also be more arbitrarily defined according the specific mission and goals of a park or reserve.

Why consider the reference condition when it may be unrecoverable in new climates? An established reference condition could be useful in considering adaptations to climate change in at least two ways. If the reference condition provides greater opportunity for species or populations to adapt to changing climate, then it offers a goal for protection or restoration. For example, removing migration barriers or restoring natural flow regimes to some rivers could allow cold water fishes to find suitable thermal conditions. Enlarging protected areas, as was recently accomplished by the Great Barrier Reef Marine Park in Australia, may provide refugia for coral reef species currently experiencing increased bleaching events that are relatively safe from other human pressures (Olsson and others 2008). Alternatively, if the reference condition is highly dependent on past climate conditions, knowledge that the conditions that produced the reference state are irretrievable can reinforce the need for adaptation to new conditions. Historical or paleohistorical records can reveal whether current species assemblages have been present for centuries to millennia, whether they are adapted to current conditions, or whether they are relict, persisting through biological inertia (Willis and Birks 2006). Scientific evidence that past and highly valued conditions are no longer attainable may provide the incentive to plan for ecosystems that are sustainable under future conditions (Choi 2007).

\section{Monitoring and Assessment Programs}

Many national parks and reserves monitor indicators of change. Are robust indicators measured at the appropriate frequencies for detecting and then managing climatecaused change? Recurring review of what is measured and why, aided with insight from experts or the scientific literature, can help ensure that climate change effects on resources designated as high priority (see section "Prioritizing Resources and Processes at Risk", above) do not go undetected. Useful indicators are understandable to multiple audiences, including scientists, policy makers, managers and the public; they show status over time. There should be a clear, transparent scientific basis both for assigning a given condition to the indicator or drawing 
inference from the condition of the indicator to the phenomenon for which it serves as a surrogate, and for triggering a management activity (Harwell and others 1999).

Assessment of the effects of climate change involves tracking the indicators and their major drivers to detect trends, previously identified thresholds, or deviation away from an established reference condition. The understanding gained from studying past ranges of variability will be the essential starting point for projecting ecosystem behavior under possible future climates (Milly and others 2008) and initiating management intervention in advance of an anticipated but undesired change. Simulation and statistical models that are invaluable tools for forecasting need to be parameterized with or tested against physical and biological information that are often the same indicators used to assess existing responses to change. It is important, therefore, to consider data requirements for models when choosing which environmental attributes to monitor.

\section{Adapting to Climate Change}

There are large uncertainties associated with projecting climate change, its effects, and the influence of human actions on those effects. Uncertainties particular to resource management include both scientific uncertainty and social uncertainty, or the cultural and organizational capability to respond (Lee 1993).

\section{Coming to Terms with Scientific Uncertainty}

There are at least three different categories of climate change effects, each associated with a different level of uncertainty: foreseeable changes, imaginable changes, and unknown and therefore surprising changes. Projections of climate change effects are generally accepted if changes are generally understood and accumulating evidence continues to sustain the projections. For instance, there is high confidence that atmospheric carbon dioxide concentrations will increase, sea levels will rise, snow packs across most of North America will shrink, global temperature will increase, fire seasons will become longer and more severe, and the severity of storms will increase (IPCC 2007). We refer to a given change as foreseeable if there is a fairly robust model (either conceptual or quantitative) describing relationships among system components and drivers, and if there are sufficient theory, data, and understanding to develop credible projections. While the magnitude or timing of foreseeable changes cannot be projected precisely, in most regions we can estimate the direction and possible range of some future conditions. For example, a 40 -year record shows that snow is melting increasingly earlier in the spring in the northeastern United States and montane western United States (Stewart and others 2005; Hodgkins and Dudley 2006). There is a strong understanding from the physical sciences of why the timing of snowmelt is likely to change in regions with winter and spring temperatures between -3 and $0{ }^{\circ} \mathrm{C}$ as the climate warms (Knowles and others 2006).

Foreseeable changes are sufficiently certain to begin planning to address the effects of earlier snowmelt. Plans could include establishing or protecting refugia for valued aquatic organisms at risk at higher elevations or latitudes, removing barriers to natural species migrations, protecting multiple populations as a hedging strategy to reduce overall risk, or restoring riparian vegetation to shade river reaches. As the risk of fire increases, it might be appropriate to consider moving infrastructure out of fire-prone areas and restricting visitor access to fire-prone areas during fire seasons to lower the incidence of accidental fires. Many parks, such as Yosemite National Park, have been managing fuels and fire for decades, and have extensive prescriptive documents that describe where and how to manage in specific locations (Final Yosemite Fire Management Plan 2004). Continued applicability of methods that have been effective in the past, however, requires regular review of prescriptive methods because, as stated above, historic ranges of variability in natural disturbance cycles may not be appropriate targets in a different climate.

The second category of climate change includes changes that are known or imaginable, but whose effects are difficult to predict with certainty. During the warm drought of the early 2000s, extraordinary levels of forest mortality affected Bandelier National Monument in the Jemez Mountains of northern New Mexico (Allen 2007). Similar forest dieback had occurred in the region in the 1950s, when the lower extent of the ponderosa pine zone in Bandelier National Monument retreated upslope by as much as $2 \mathrm{~km}$ in less than five years in response to severe drought and an associated outbreak of bark beetles (Allen and Breshears 1998; Allen 2007). Scientists cannot yet model species-specific tree mortality thresholds in response to climate stress on real landscapes (McDowell and others 2008; Purves and Pacala 2008), making it difficult to project when such extensive, rapid ecological shifts will occur. Planning for these types of rare but major events requires that societal mechanisms be put in place to reduce the damage they cause. Mechanisms could include erecting physical barriers to minimize erosion that may occur given forest dieback, removing infrastructure from river corridors to minimize flood damage, maintaining corridors for species migration, or collecting and storing native seeds.

The third category of climate change is unknown or unknowable changes that have not previously been experienced by humans. Nonlinear interactions among system 
components and drivers can lead to surprise (Burkett and others 2005). Perhaps the greatest uncertainties in projecting climate change and its effects are associated with the interaction of climate change and other human activities. Novel ecosystems may emerge in response to the synergistic and cumulative interactions among multiple system components and stressors, such as new barriers or pathways to species movement, disruption of nutrient cycles, or the emergence of new diseases (Hobbs and others 2006).

\section{Management Under Uncertainty}

A recent study notes the frequency of ecological surprises and attributes the occurrence at least partly to natural system complexity (Doak and others 2008). National parks and reserves are complex systems within complex landscapes. Doak and others (2008) suggest complexity and surprises reinforce the need for management plans that are highly precautionary, rather than plans that assume specific management actions will have specific outcomes. For example, the intentional introduction of a freshwater shrimp (Mysis relicta) to Flathead Lake, Montana, and other lakes in the western United States lakes with the intent of increasing salmon production resulted in substantial reductions in the abundance of native fishes and fish consumers such as bald eagles. Not only was shrimp behavior incompatible with the feeding strategy of salmon, but the shrimp rapidly consumed the zooplankton that had been a major food source for salmon (Stanford and Ellis 2002).

The two major factors that influence selection of strategies for managing complex systems are the degree (and type) of uncertainty and the extent to which key ecological processes can be controlled (Fig. 1). Different strategic approaches (Fig. 1) are appropriate for different types of management and while not interchangeable, the lessons

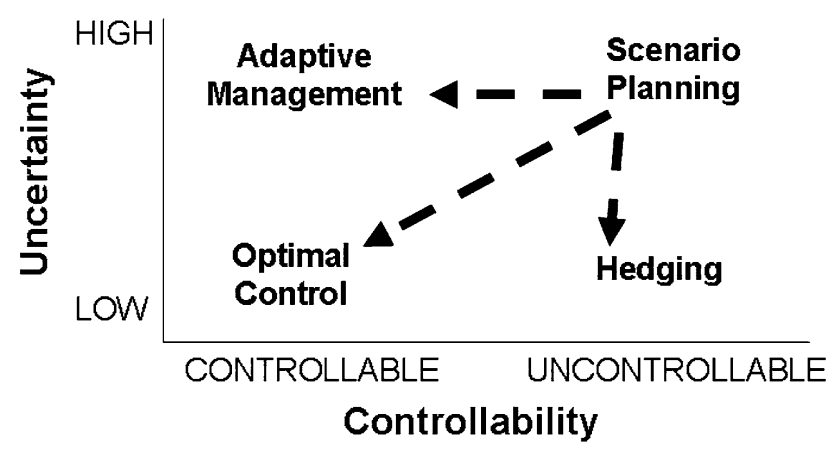

Fig. 1 Scenario planning is appropriate for systems in which there is a lot of uncertainty that is not controllable. In other cases, optimal control, hedging, or adaptive management may be appropriate responses. Adapted from Peterson and others (2003) learned from application of one approach can inform the decisions on whether to employ the other approaches.

\section{Optimal Control and Hedging}

Most current approaches toward resource management in national parks and reserves are appropriate when uncertainty is low and specific activities are likely to achieve a clear outcome. Management of wildlife (e.g., culling, birth control, or reintroduction of top predators) and non-native, invasive plants and animals are examples of optimal control, although our understanding of processes and limiting factors is often insufficient to have high confidence in the outcomes of specific management actions (Ripple and Beschta 2005; Messing and Wright 2006). Optimal control does not always produce desired results due to ecosystem complexity and the myriad opportunities for surprise, but it lends itself well to many agency policies that require specific performance standards for reporting or meeting legal requirements (Joyce and others 2008).

Hedging strategies are particularly useful in situations where there is limited ability to control all key variables (Peterson and others 2003). Placing large woody debris in a stream is a hedging strategy that improves habitat quality for anadromous fish, alleviating one of the many stresses that hinder fish survival (Bilby and Bisson 1998). For some species, connecting networks of reserves through migratory corridors hedges against the risk of extirpation associated with isolated populations. The establishment of parks and reserves itself is a hedging strategy against loss of species and their habitats (Roberts 2000).

\section{Adaptive Environmental Assessment and Management}

Adaptive environmental assessment and management refers to a set of processes to integrate learning with management actions (Holling 1978; Walters 1986; Lee 1993). It is highly applicable to circumstances where there is ability to influence an ecological process but uncertainty as to the best methods. The processes focus on developing hypotheses to describe (1) how specific ecological dynamics operate and (2) how human interventions may affect the ecosystem. Adaptive environmental assessment is substantially different from environmental assessments routinely conducted within frameworks such as the National Environmental Policy Act (NEPA). The NEPA process presumes certainty of effects and outcomes, and generally minimizes or ignores uncertainties. Adaptive environmental assessment and management, by contrast, highlights uncertainty. Managers design actions that specifically test uncertainties about ecosystem dynamics and outcomes of proposed interventions. The objectives of management actions explicitly include learning (hence reduction of uncertainty). 
Adaptive management can be either active or passive. Active adaptive management involves direct manipulation of key ecological processes to test understanding of relationships among system components and drivers and to examine the effects of policies or decisions, such as the flood release experiments of 1996 and 2004 in the Grand Canyon of the Colorado River (Walters and others 2000). Passive adaptive management relies on historical information to construct a conceptual model of how a system works and how it will respond to changing conditions (NRC 2003). Whether active or passive, information gathered throughout the iterative adaptive management cycle is used to increase ecological understanding, and adjust and refine management (Walters and Holling 1990).

Adaptive management can be successful in systems that meet both ecological and social criteria: sufficient ecological resilience to deterministic and stochastic change, and a willingness of managers, their administrators, and the public to experiment and participate in a formal structure for learning. Ecological resilience buffers the system from the potential failure of management actions that were based upon incomplete understanding. Trust and cooperation are necessary for implementing management actions that are designed to meet learning and other social objectives. Flow experiments in the Grand Canyon illustrate adaptive management at its best, when trust among stakeholders and managers allows some environmental risk to occur in order to build better understanding and better resource management (Hughes and others 2007). Unfortunately, the Grand Canyon experiments also illustrate how fragile relations between managers and stakeholders can be; a legal complaint that existing management activities, including experiments, were violating the U.S. Endangered Species Act was filed in 2008 by several stakeholders (http://www. grandcanyontrust.org/programs/water/colorado.php).

\section{Scenario-Based Planning}

Scenario-based planning is a process, usually qualitative, that involves exploration of a wide set of alternative futures (Carpenter 2002; Peterson and others 2003; Raskin 2005). Scenario development is used routinely to assess a variety of environmental resource issues (NRC 1999). A finite number of scenarios, typically three to five, can be extremely useful for helping to develop and implement plans, and also can minimize the frustration that comes from having to deal with uncertainty. Research on the rate, extent, or permanence of climate change-induced effects on species and ecosystems can inform the scenarios; in other words, scenarios will be stronger with a scientific foundation. Either passive or active contingency plans can be deployed for both (1) trends that are observed and have a high probability of continuing, and (2) events with low probability but high risk that result from any combination of climate change and other stresses.

Scenario planning and development of contingency plans can lead to several levels of preparedness. For example, plans can be constructed to trigger an optimal control or hedging action if a threshold is crossed. Routine monitoring of indicators of environmental condition, as described above, determines when thresholds are being approached. Scenarios should be designed to address how climate change will affect current resource management issues. If habitat recovery plans for endangered species, for instance, do not take future climate change into account, recovery goals will be even more difficult to achieve than at present. Doubt about the proper management path to take for recovery, however, might provide the trigger to implement adaptive management.

Scenarios provide the opportunity to resolve conflicts among management goals or regulations. Planning exercises can identify where potential conflicts may occur under various climate change and management scenarios, and address the balance between short-term costs and longterm benefits. Tradeoffs between air quality and the use of fire for ecosystem restoration and maintenance already are made, for instance (McKenzie and others 2006). Management responses to scenarios should consider the degree of uncertainty associated with drivers and their effects, the resources available, and legal mandates as well as social and economic consequences. Public involvement in scenario building at all levels, from individual park or region to national, will not only prepare people for possible future outcomes, but will help build support if goals need to be modified.

\section{Addressing Social Uncertainty}

The uncertainties associated with projections of climate change and its effects are substantial. Failure may occur regardless of the intent to implement a "correct" action. We suggest that parks and reserves consider implementing human resource management policies that actively manage for uncertainty. These have been called "safe-to-fail" policies. This type of approach is employed in fields where uncertainty is actively managed through flexible designs that adjust to changing conditions, such as engineering systems (e.g., air traffic control or electric power distribution) (Neufville 2003). When applied to a natural resource management activity, safe-to-fail policies resemble adaptive management, because a safe-to-fail experiment or action is undertaken only where there is confidence that the system can recover from failure without irreversible damage to the targeted resource. A safe-to-fail 
policy for human resources (e.g., careers and livelihoods) emphasizes the cooperative relationship between supervisor and staff or between agencies and stakeholders. The uncertainty inherent in achieving desired future conditions or trajectories strongly argues against management "by the book." Safe-to-fail human resource policies empower individuals to take reasoned management risks without concern for retribution. Although a culture of trust between front line managers and their supervisors already exists at smaller scales in many public and private organizations, it might need to be expanded and enhanced. Lack of communication, especially about the implications of uncertainty associated with resource management in a changing climate, can lead to distrust, and result in withdrawal of decision-making authority and the imposition of regulations. Guidelines that codify the intellectual process by which decisions are made, rather than the decisions themselves, can lead to more effective resource management under uncertainty. If supervisors and upper level managers are satisfied that decisions are being made in a logical thoughtful way, it may promote the culture of trust at all levels within agencies and bureaus.

Even highly reasoned actions have some potential to go awry, especially as climate changes. Although clearly not desired, failures provide opportunities for learning. Continued and expanded public education about the complexity of resource management, transparency in the decisionmaking process, frequent public updates on progress or setbacks, and internal agency efforts that promote trust and respect for professionals are all important methods for promoting more nuanced management efforts. Developing a culture of trust between public servants and their public will require all these techniques, and will be important, if not critical, to implementing practices to adapt to climate change.

\section{Incorporating Climate Change Considerations into Natural Resource Management}

Given that climate change is already affecting natural and managed systems, it would be prudent to begin implementing adaptation strategies immediately. As noted above, management actions that increase resilience may be most effective in the near term, but it will be important to reevaluate those actions frequently given that analogs from the past may not be effective for managing future environments.

Over the next few decades, specific management actions may help parks and reserves meet their conservation goals. Resilience of physical and biological resources in their current form to climate change may be increased through thoughtful reduction of anthropogenic disturbances, protection of refugia, and possibly relocation of priority species to more favorable climates. While it may be tempting to promote a return of disturbance regimes or population dynamics to some "pre-human intervention" range of natural variability, this option must be considered cautiously. Ecosystems change in many ways as a result of management, and unexpected results may occur if restoration is focused on only one kind of process. A historic flow and temperature regime for the Colorado River below Glen Canyon Dam, for instance, could allow nonnative warm water fishes that are now established to move upstream and compete with endangered fishes (Gloss and others 2005).

In addition to the direct consequences of climate change to park resources, we know that interactions of climate with other stressors will have major influences on park and reserve resources (McKenzie and others 2006). One of the most basic actions to slow or mitigate some effects of climatic change, therefore, is to reduce the magnitude of other human-caused disturbances to park and reserve ecosystems (e.g., Hansen and others 2003; Welch 2005). Minimizing sources of pollution, reducing the competition between non-native and native species, controlling the spread of disease, reversing trends of habitat fragmentation and loss, decreasing the extent of poaching or other types of resource exploitation, and restoring natural disturbance regimes should increase ecosystem resilience to changing climate.

Among the challenges for parks and reserves are protection and restoration of native species. Species distributions are changing as the climate changes. Changing distributions are evident from observations of gradual latitudinal and elevational migrations (Edwards and others 2005; Parmesan 2006) and in extensive mortality of trees, such as piñon in Bandelier National Monument (Allen 2007). A recent study suggests that by 2100 , the climate of between $4 \%$ and $39 \%$ of Earth will be different from conditions that currently exist anywhere on the planet (Williams and others 2007). Changes in species distributions occurring at all spatial extents may confound the ability of parks and reserves to restore current or past composition of species assemblages. It will be important to have frank discussions regarding the desirability of novel assemblages and ecosystems (Hobbs and others 2006). Individual species of plants and animals will immigrate into parks and reserves as they seek resources and favorable climatic conditions. The definition of invasive may need to be relaxed, and corridors connected to parks and reserves may need protection or restoration to accommodate these movements. Greater understanding of the constraints and selective pressures on dispersal will be important for deciding which new residents are welcome (Koko and López-Sepulcre 2006). In some cases, hardy 
invasive species may be desirable if they serve to maintain ecosystem function or act as a "nurse species" for the establishment of natives in new locations (D'Antonio and Meyerson 2002).

\section{Management Policies and Guidelines}

All parks and reserves operate within codified guidelines that define the scope of management activities-both allowed and required-to meet agency missions. Often, however, the interpretation of guidelines can evolve, making it appropriate to revisit interpretations in relation to management for adapting to climate change. While resource management is implemented at individual parks and reserves, planning and support is provided at all management levels. A consistent top to bottom vision of how to incorporate climate change considerations into management could promote short- and long-term adaptation practices and a shared culture of trust. We use the U.S. National Park Service (NPS) guidelines to illustrate a history of flexible interpretation of policy in response to increased scientific understanding of ecological systems, public opinions, and desires, and new laws and administrative directives. Past flexibility can serve as a precedent for future climate change adaptation practices and policies.

The NPS operates under its original Organic Act of 1916 "to conserve the scenery and the natural and historic objects and the wild life therein and to provide for the enjoyment of the same in such manner and by such means as will leave them unimpaired for the enjoyment of future generations" (U.S. Congress 1916). The 1970 General Authorities Act and the 1978 "Redwood Amendment" to the Organic Act strengthened its conservation mission by clarifying that the "fundamental purpose" of the national park system is to conserve park resources and values. National parks also abide by guidelines of the Wilderness Act of 1964, the Wild and Scenic Rivers Act of 1968, the Clean Water Act of 1972, the Endangered Species Act of 1973, and the Clean Air Act of 1990.

Although its mission has remained mostly unchanged, the NPS has undergone substantial evolution in management philosophy since 1916. Prior to the 1960s, parks actively practiced fire suppression, aggressive wildlife management (e.g., culling some species and providing supplemental food to others), and application of pesticides to prevent irruptions of native insects. Development of ski slopes and golf courses within park boundaries was congruent with visitor enjoyment. During the 1960s, the Leopold Report on Wildlife Management in National Parks, the 1964 Wilderness Act, and the growth of the environmental movement ushered in a different management philosophy (Leopold 1963; Sellars 1997). Policies changed as managers began to consider natural controls on the size of wildlife populations. Some park managers closed ski lifts and golf courses, deciding that these uses were not congruent with their mission. Implementation of the Wilderness Act of 1964 restricted mechanized and many other activities in designated or proposed wilderness areas within parks.

National park status, often considered the most fundamental of mandates, is not necessarily conferred in perpetuity. Twenty-four units of the U.S. national park system either have been deauthorized or transferred to other management jurisdictions (National Park Service Bureau Historian 2006). Fifteen areas were transferred to other agencies because their national significance was marginal, and others were deauthorized because their location was inaccessible to the public. The management of five reservoirs was consigned to the Bureau of Reclamation (National Park Service 2003). Consider that Fossil Cycad National Monument in South Dakota, by contrast, was deauthorized by Congress in 1957 due to near-complete loss of the fossil resource as a result of collecting activity (National Park Service 1998).

This example illustrates that management policies have evolved in response to new knowledge or societal desires. Circumstances change, and to its great credit, the National Park Service has changed with them. Perceptions of what are appropriate management actions evolve in light of new knowledge. The precedent of incorporating new or different policies, particularly those informed by scientific understanding, will serve the National Park Service well in the face of accelerating climate change.

\section{Management at Multiple Scales}

Complex ecological systems operate and change at multiple spatial and temporal scales. The scales at which ecological processes operate often will dictate the appropriate scales at which management institutions should be developed. Migratory bird management, for instance, requires international collaboration; ungulates and carnivores with large home ranges call for regional collaboration; marine preserves require cooperation among many stakeholders. All are examples where working solely within park or reserve boundaries will be ineffective. Similarly, preparation for rapid events such as floods will be managed quite differently than responses to climate impacts that occur over decades. Species may be able to move to locations with favorable climate and other environmental conditions over time if natural areas and open space remain connected. There are several examples of management of park resources within larger regional or ecosystem contexts. The Greater Yellowstone Coordinating Committee (http://www. gycd.org) and the Southern Appalachian Man and the Biosphere (SAMAB; http://www.samab.org/) are building 
relationships across jurisdictional boundaries that will allow effective planning for species and processes to adapt to climate change. Olympic, Channel Islands, American Samoa, Everglades, Point Reyes, and other coastal parks cooperate with many other state and federal agencies in advising and managing national marine sanctuaries. These ecoregional consortia can serve as models for other park areas as they begin to address the multiple challenges that originate outside park boundaries.

\section{Concluding Remarks}

National parks and reserves worldwide contain some of the least human-modified ecosystems on Earth. Many of them are internationally recognized as Biosphere Reserves or World Heritage sites. Their protection becomes increasingly important as these systems become more rare (Baron 2004). However, all ecosystems are responding to climate change and other human-caused disturbances. Effective adaptation requires that agencies, managers, scientists, and the public think differently from in the past about how to manage natural resources. We suggest that given the high level of uncertainty associated with forecasting future conditions and the ability to manage for specific goals, national parks and reserves pay ongoing attention to current scientific discoveries and add adaptive management and scenario planning to their list of management tools. Fostering a culture that values (and shares) the intellectual thought process behind specific resource management actions can help build trust between managers, their supervisors, and the public that will aid in adaptation. A robust and diverse set of strategies will be needed to confront the uncertainties and complexities of climate change, and there is little time to wait.

Acknowledgments We thank the U.S. Climate Change Science Program and the Lead Authors of Science and Assessment Product 4.4, Susan Julius and Jordan West. This is a product of the U.S. Geological Survey's Western Mountain Initiative. Advice, comments, and reviews from Abby Miller, Bob Krumenaker, David Graber, Vaughn Baker, Jeff Connor, and Ben Bobowski strengthened the manuscript. Participants in a November 2006 workshop provided valuable comments and context.

Open Access This article is distributed under the terms of the Creative Commons Attribution Noncommercial License which permits any noncommercial use, distribution, and reproduction in any medium, provided the original author(s) and source are credited.

\section{References}

Allen CD (2007) Cross-scale interactions among forest dieback, fire, and erosion in northern New Mexico landscapes. Ecosystems 10:797-808
Allen CD, Breshears DD (1998) Drought-induced shift of a forestwoodland ecotone: rapid landscape response to climate variation. Proceedings of the National Academy of Sciences 95:14839-14842

Araújo MB, Cabeza M, Thuiller W, Hannah L, Williams PH (2004) Would climate change drive species out of reserves? An assessment of existing reserve-selection methods. Global Change Biology 10:1618-1626

Baron JS (2004) Research in National Parks. Ecological Applications $14: 3-4$

Baron JS, Allen CD, Fleishman E, Gunderson L, McKenzie D, Meyerson L, Oropeza J, Stephenson N (2008) National parks. In: Julius SH, West JM (eds) Preliminary review of adaptation options for climate-sensitive ecosystems and resources. A Report by the U.S. Climate Change Science Program and the Subcommittee on Global Change Research. U.S. Environmental Protection Agency, Washington, DC, USA, pp 4-1 to 4-68

Bilby RE, Bisson PA (1998) Function and distribution of large woody debris. In: Naiman RJ, Bilby RE (eds) River ecology and management. Springer, New York, pp 324-339

Burkett V, Wilcox D, Stottlemyer R, Barrow W, Fagre D, Baron J, Price J, Nielsen JL, Allen CD, Peterson DL, Ruggerone G, Doyle $T$ (2005) Nonlinear dynamics in ecosystem response to climatic change: case studies and policy implications. Ecological Complexity 2:357-394

Carpenter SR (2002) Ecological futures: building an ecology of the long now. Ecology 83:2069-2083

Choi YD (2007) Restoration ecology to the future: a call for a new paradigm. Restoration Ecology 15:351-353

D’Antonio C, Meyerson LA (2002) Exotic plant species as problems and solutions in ecological restoration: a synthesis. Restoration Ecology 10:703-713

Doak DF, Estes JA, Halpern BS, Jacob U, Lindberg DR, Lovvorn J, Monson DH, Tinker MT, Williams TM, Wootton JT, Carroll I, Emmerson M, Micheli F, Novak M (2008) Understanding and predicting ecological dynamics: are major surprises inevitable? Ecology 89:952-961

Edwards ME, Brubaker LE, Lozhkin AV, Anderson PM (2005) Structurally novel biomes: a response to past warming in Beringia. Ecology 86:1696-1703

Final Yosemite Fire Management Plan (2004) http://www.nps.gov/ archive/yose/planning/fire/

Gloss SP, Lovich JE, Melis TS (eds) (2005) The state of the Colorado river ecosystem in grand canyon. USGS Circular 1282, $220 \mathrm{pp}$

Groffman PM, Baron JS, Blett T, Gold AJ, Goodman I, Gunderson LH, Levinson BM, Palmer MA, Paerl HW, Peterson GD, Poff NL, Rajeski DW, Reynolds JW, Turner MG, Weathers KC, Wiens J (2006) Ecological thresholds: the key to successful environmental management, or an important concept with no practical application? Ecosystems 9:1-13

Gunderson LH (2000) Ecological resilience in theory and application. Annual Review of Ecology and Systematics 31:425-439

Hansen LJ, Biringer JL, Hoffman JR (2003) Buying time: a user's manual for building resistance and resilience to climate change in natural systems. World Wildlife Foundation, Washington, DC

Harwell MA, Myers V, Young T, Bartuska A, Gassman N, Gentile JH, Harwell CC, Appelbaum S, Barko J, Causey B, Johnson C, McLean A, Ron S, Templet P, Tosini S (1999) A framework for an ecosystem integrity report card. BioScience 49:543-556

Hobbs RJ, Arico S, Aronson J, Baron JS, Bridgewater P, Cramer VA, Epstein PR, Ewel JJ, Klink CA, Lugo AE, Norton D, Ojima D, Richardson DM, Sanderson EW, Valladares F, Vilà M, Zamora R, Zobel M (2006) Novel ecosystems: theoretical and management aspects of the new ecological world order. Global Ecology and Biogeography 15:1-7

Hodgkins GA, Dudley RW (2006) Changes in the timing of winterspring streamflows in eastern North America, 1913-2002. 
Geophysical Research Letters 33:L06402. doi:10.1029/ 2005GL025593

Holling CS (1973) Resilience and the stability of ecological systems. Annual Review of Ecology and Systematics 4:1-23

Holling CS (1978) Adaptive environmental assessment and management. Blackburn Press, Caldwell, NJ

Hughes TP, Gunderson LH, Folke C, Baird AH, Bellwood D, Berkes F, Crona H, Helfgott A, Leslie H, Norberg J, Nyström M, Olsson P, Österblom H, Scheffer M, Schuttenberg H, Steneck RS, Tengö M, Troell M, Walker B, Wilson B, Worm B (2007) Adaptive management of the Great Barrier Reef and the Grand Canyon World Heritage Areas. Ambio 36:586-593

Intergovernmental Panel on Climate Change (IPCC) (2007) Climate change 2007: the physical science basis. Summary for policymakers

Joyce LA, Blate GM, Littell JS, McNulty SG, Millar CI, Moser SC, Neilson RP, O'Halloran K, Peterson DL (2008) National forests. In: Julius SH, West JM (eds) Preliminary review of adaptation options for climate-sensitive ecosystems and resources. A Report by the U.S. Climate Change Science Program and the Subcommittee on Global Change Research. U.S. Environmental Protection Agency, Washington, DC, USA, pp 3-1 to 3-127

Knowles N, Dettinger MD, Cayan DR (2006) Trends in snowfall versus rainfall in the Western United States. Journal of Climate 19:4545-4559

Koko H, López-Sepulcre A (2006) From individual dispersal to species ranges: perspectives for a changing world. Science 313:789-791

Landres PB, Morgan P, Swanson FJ (1999) Overview of the use of natural variability concepts in managing ecological systems. Ecological Applications 9:1179-1188

Lee KN (1993) Compass and gyroscope: integrating science and politics for the environment. Island Press, Washington, DC

Leopold AS (1963) Wildlife management in the National Parks. Report submitted by Advisory Board on Wildlife Management, appointed by Secretary of the Interior Udall, pp 1-23

McDowell N, Pockman WT, Allen CD, Breshears DD, Cobb N, Kolb T, Sperry J, West A, Williams D, Yepez EA (2008) Mechanisms of plant survival and mortality during drought: why do some plants survive while others succumb to drought? Tansley Review, New Phytologist. doi:10.1111/j.1469-8137.2008.02436.x

McKenzie D, Gedalof Z, Peterson DL, Mote P (2004) Climatic change, wildfire, and conservation. Conservation Biology 18:890-902

McKenzie DH, O'Neill S, Larkin NK, Norheim RA (2006) How will climatic change affect air quality in parks and wilderness? In: Harmon D (ed) Proceedings of the 2005 George Wright Society annual meeting

Messing RH, Wright MG (2006) Biological control of invasive species: solution or pollution? Frontiers in Ecology and Environment 4:132-140

Millar CI, Stephenson NL, Stephens SL (2007) Climate change and the forests of the future: managing in the face of uncertainty. Ecological Applications 17:2145-2151

Milly PCD, Betancourt J, Falkenmark M, Hirsch RM, Kundzewicz ZW, Lettenmaier DP, Stouffer RJ (2008) Stationarity is dead: whither water management? Science 319:573-574

National Park Service (1998) Natural resource year in review, 1997, Publication D-1247. Department of the Interior

National Park Service (2003) National Park Service history: former National Park System units: an analysis. National Park Service. http://www.nps.gov/history/history/hisnps/NPSHistory/former parks.htm. Accessed on 7-13-2007

National Research Council (1999) Our common journey: a transition toward sustainability. National Academy Press, Washington, DC
National Research Council (2003) Adaptive monitoring and assessment for the comprehensive everglades restoration plan. National Academies Press, Washington DC

Neufville R (2003) Real options: dealing with uncertainty in systems planning and design. Integrated Assessment 4:26-34

NPS Bureau Historian (2006) Former National Park System units: an analysis. National Park Service. http://www.cr.nps.gov/history/ hisnps/NPSHistory/formerparks.htm. Accessed on 4-6-2007

Olsson P, Folke C, Hughes T (2008) Navigating the transition to ecosystem-based management of the Great Barrier Reef, Australia. Proceedings of the National Academy of Sciences of the United States of America 105:9489-9494

Parmesan C (2006) Ecological and evolutionary responses to recent climate change. Annual Review of Ecology, Evolution and Systematics 37:637-669

Parsons DJ (2004) Supporting basic ecological research in U.S. National Parks: challenges and opportunities. Ecological Applications 14:5-13

Peterson GD, Cumming GS, Carpenter SR (2003) Scenario planning: a tool for conservation in an uncertain world. Conservation Biology 17:358-366

Porter E, Johnson S (2007) Translating science into policy: using ecosystem thresholds to protect resources in Rocky Mountain National Park. Environmental Pollution 149:268-280

Purves D, Pacala S (2008) Predictive models of forest dynamics. Science 320:1452-1453

Raskin PD (2005) Global scenarios: background review for the Millennium Ecosystem Assessment. Ecosystems 8:133-142

Ripple WJ, Beschta RL (2005) Linking wolves and plants: Aldo Leopold on trophic cascades. BioScience 55:613-621

Roberts CM (2000) Selecting marine reserve locations: optimality versus opportunism. Bulletin of Marine Science 66:581-592

Sellars RW (1997) Preserving nature in the national parks. Yale University Press, New Haven

Stanford JA, Ellis BK (2002) Natural and cultural influences on ecosystem processes in the Flathead River Basin (Montana and British Columbia). In: Baron JS (ed) Rocky Mountain futures: an ecological perspective. Island Press, pp 269-284

Stewart IT, Cayan DR, Dettinger MD (2005) Changes toward earlier streamflow timing across western North America. Journal of Climate 18:1136-1155

Stoddard JL, Larsen DP, Hawkins CP, Johnson RK, Norris RH (2006) Setting expectations for the ecological condition of streams: the concept of reference condition. Ecological Applications $16: 1267-1276$

U.S. Congress (1916) The National Park Service Organic Act. National Park Service, 16 U.S.C. 1, 2, 3, and 4

Walters C (1986) Adaptive management of renewable resources. McGraw Hill, New York

Walters CJ, Holling CS (1990) Large-scale management experiments and learning by doing. Ecology 71:2060-2068

Walters C, Korman J, Stevens LE, Gold B (2000) Ecosystem modeling for evaluation of adaptive management policies in the Grand Canyon. Conservation Ecology 4:1 (online)

Welch D (2005) What should protected areas managers do in the face of climate change? The George Wright Forum 22:75-93

Williams JW, Jackson ST, Kutzbach JE (2007) Projected distributions of novel and disappearing climates by 2100 AD. Proceedings of the National Academy of Sciences of the United States of America 104:5738-5742

Willis KG, Birks HJB (2006) What is natural? The need for a longterm perspective in biodiversity conservation. Science 314:1261 